\title{
Temporal variation in group aggressiveness of honeybee (Apis mellifera) guards*
}

\author{
Hadassah Troen, Irit Dubrovsky, Ram TAMIR, Guy BLOCH \\ Department of Evolution, Systematics and Ecology, The Alexander Silberman Institute of Life Sciences, \\ The Hebrew University of Jerusalem, 91904 Jerusalem, Israel
}

Received 29 October 2007 - Revised 5 December 2007 - Accepted 5 December 2007

\begin{abstract}
Little is known about the temporal organization of defensive behavior in honeybees. We studied "guards", the best-characterized class of colony defenders. We synchronized small groups under a lightdark illumination regime (LD), and video recorded their aggression toward an intruder bumblebee worker. In 1 out of 3 trials (each trial with a different source colony), the latency before the first attack was longer during the night in LD, or subjective night in constant conditions (DD); a similar trend was observed in DD in the two other trials. In 2 out of 3 trials, the number of stinging attempts varied with highest levels during the day in DD, but not in LD. There was a similar trend for the number of biting events. These findings reveal temporal variation in aggression under constant conditions, consistent with the hypothesis that the circadian clock influences guard aggressiveness. Nevertheless, the variability between LD and DD and across colonies calls for additional studies before reaching a definitive conclusion.
\end{abstract}

\section{honeybees / aggression / colony defense / circadian rhythm / division of labor}

\section{INTRODUCTION}

Social insects allocate labor to defend their colonies against predators, parasites, robbers, and other intruders. There has been significant progress in research on the mechanisms and regulation of defensive behavior in honeybees (reviewed in Breed et al., 2004), but little is known about its temporal organization. Although animals in general are commonly assumed to be more aggressive at times when they are normally most active (Landau, 1975), this may not be applicable to the honeybee. There are reports suggesting that the diurnal honeybee is remarkably aggressive at night; bees that are disturbed at night typically crawl instead of fly, and are quick to sting (e.g., Caron, 2000; unpublished observations). Although to the best of our knowledge,

Corresponding author: Guy Bloch,

bloch@vms.huji.ac.il

* Manuscript editor: Stan Schneider these claims of high aggressiveness at night have not been tested empirically, being aggressive at night makes functional sense. This is because some of the most dangerous enemies of honeybees, including bears, skunks, and the Greater Wax Moth (Galleria mellonella), are nocturnal attackers. One hypothesis is that at least some of the bees involved in colony defense are most aggressive at night (whereas other colony defenders are perhaps more aggressive at other times). An alternative hypothesis is that bees specializing in defensive activities are aggressive around-the-clock with no circadian rhythms. Previous studies indeed show that the division of labor in honeybee colonies is associated with plasticity in circadian rhythms, with "nurse" bees attending the brood around-the-clock. In this case, activity with no circadian rhythms is thought to improve care for the brood. Foragers on the other hand, have strong circadian rhythms that are necessary for timing visits to flowers, and for time-compensated sun-compass navigation 
(reviewed in Moore, 2001; Bloch, 2008). The expression of circadian rhythmicity is also influenced by developmental processes. Studies in various environments and social conditions show that newly emerged bees typically have no circadian rhythms in activity, but they develop significant circadian rhythms over the course of their first three weeks of life as adults (Moore et al., 1998; Moore, 2001; Meshi and Bloch, 2007).

To begin exploring the temporal organization of defensive behavior we studied diurnal and circadian rhythms in the level of aggressiveness in small groups of "guard bees". Guarding is a specialized task in the defensive behavior of bee colonies that is performed by only a small proportion $(\sim 10 \%)$ of a colony's worker population. Guards patrol the hive entrance, inspect incomers, and defend the colony against predators, parasites, and robbers. These are usually middleaged workers (13-16 days old; reviewed in Winston, 1987; Breed et al., 2004). Bees at this age typically have circadian rhythms in activity (Moore et al., 1998; Moore, 2001; Bloch, 2008). However, this does not lead directly to the conclusion that guards are rhythmic because the social environment and worker task influence circadian rhythmicity independently of chronological age. For example, old foragers that were induced to revert to brood care activity switched back to around-the-clock activity (Bloch and Robinson, 2001). Typical age nurse bees that are active around-the-clock in the hive show strong circadian rhythms shortly after transfer to individual cages in the laboratory (Shemesh et al., 2007; Shemesh and Bloch, unpublished observations). Perhaps guarding, like nursing behavior, is associated with around-the-clock activity.

\section{MATERIALS AND METHODS}

\subsection{Bees}

We maintained honeybee (Apis mellifera L.) colonies in the field, at the bee research facility on the Edmond J. Safra (Givat Ram) campus of the Hebrew University of Jerusalem, Jerusalem, Israel, according to standard commercial techniques. Honeybees in our colonies were derived from a mixture of European races typical to this region. We identified a guard as a worker bee that patrols the landing board in front of the hive entrance and inspects incoming bees by antennation. Guards typically quickly approach bees that are landing and show a characteristic posture when not moving about - they stand with their forelegs off the ground and their antennae pointing forward (Moore et al., 1987; Breed et al., 1992).

\subsection{Experimental procedure}

There are several assays for measuring the level of aggressiveness in individuals, groups of bees, and intact colonies (reviewed in Kolmes and FergussonKolmes, 1989; Breed et al., 2004). Field assays with whole colonies preserve the ecological context but suffer from potential confounding variables such as colony size, foraging activity, worker age, temperature, humidity, and the amount of empty cells - all of which may influence the level of aggressiveness. In laboratory assays for individual bees, the environment is well controlled and alarm pheromones and other non-linear group interactions have no influence, but focal bees are typically restrained and their behavior is not natural. Given this methodological trade-off, we tested several assays and eventually adopted a protocol based on the nestmate recognition test for a group of bees (Breed, 1983; Getz and Smith, 1983). This assay makes it possible to focus on an identified task group (guards) while bees are not restrained and are in a social environment that is important for the expression of defensive behavior. There are reports indicating that the aggressive response of bees in small groups correlates well with the defensive behavior of typical field colonies (Breed, 1983; Moritz et al., 1985; Breed et al., 1992). The main limitations of our assay, however, are that it is not known to what extent the social context of small groups is comparable to the situation in intact field colonies, and there is no direct measure for circadian rhythmicity in the aggressiveness of individual bees.

We used groups containing 10-12 guard bees that were collected at the hive entrance and placed inside Libfield wooden cages $(13 \times 12 \times 5.5 \mathrm{~cm}$, with a Plexiglas cover). We chose groups of this size because they express a notable level of aggression but at the same time permit effective observation on the behavior of individual bees (our preliminary experiments, data not shown). We provisioned each cage with ad libitum sugar syrup and pollen (pollen was 
not provided in the experiment with colony H4), and placed all the cages together in an environmental chamber (temp' $=29 \pm 1{ }^{\circ} \mathrm{C}$ in the experiment with colonies $\mathrm{H} 5$ and $\mathrm{H} 7,28 \pm 2{ }^{\circ} \mathrm{C}$ for colony $\mathrm{H} 4$; relative humidity $\simeq 60 \%$ ). To test the level of aggressiveness we introduced a single bumblebee (Bombus terrestris) worker into a cage with guard honeybees. A bumblebee and not a honeybee was chosen following preliminary experiments showing that the level of aggression toward a honeybee was variable and relatively low, with many trials with no detected level of aggression (similar variability was reported by Breed et al., 1992; Pearce et al., 2001). We obtained bumblebee colonies from Polyam Industries, Kibbutz Yad Mordechai, Israel, and maintained them as described in Geva et al. (2005).

Experiments typically lasted six days. We collected the guard bees on days 1 and 2, and tested the level of aggressiveness on their fifth day in the laboratory (days 5 or 6 of the experiment, respectively). Illumination regime was set to $12 \mathrm{~h}$ light: $12 \mathrm{~h}$ dark (LD) during the first 4 days (light on at 0600, 0700, 0800, in the experiments with colonies $\mathrm{H} 4, \mathrm{H} 7$, and $\mathrm{H} 5$, respectively; determined relative to the time of sunrise) and constant darkness (DD) during the last day. Three to four days in LD illumination regime are necessary for synchronizing circadian rhythms in bees (Moore, 2001); the assay in constant conditions (DD) allows for detection of internal influences on aggression. The Bombus workers were removed from their colony $6.5 \mathrm{~h}$ before the test, anaesthetized by chilling, and placed inside an "introduction tube" in which they recovered and became active again. The introduction tube was a cylinder made from a Falcon tube (diameter $=12 \mathrm{~mm}$, length $=75 \mathrm{~mm}$ ) that was open at both ends, and was fitted with a piston that was later used to push the Bombus worker into a Libfield cage with honeybees. We attempted to minimize size and age variation among introduced bumblebee workers. Five hours before the test, the focal cages were placed next to each other on shock absorbers to minimize vibrations to which bumblebees are very sensitive. This procedure allowed us to video record the cages without further handling that could arouse or irritate the bees.

We measured the level of aggressiveness every 6 hours on days 5 (in LD) and 6 (in DD) of the experiment. In the experiment with bees from colony H5, we entrained the bees for 4 days in LD and tested them only in DD on day 5. Each observation lasted $10 \mathrm{~min}$. In order to maintain sample independence, we used each bumblebee and group of hon- eybees in only one single $10 \mathrm{~min}$ assay. To initiate an aggressiveness test we connected the introduction tube to an opening of appropriate size in the wall of the test cage, and gently pushed (with the piston) the bumblebee into the cage. The behavior of the bees was observed and verbally described by the experimenter and simultaneously recorded with an infrared CCD camera (20 Hz; Sony TRV 75E or Panasonic WV-BP334) under dim red light that the bees cannot see. We took special care not to move the test cage during the introduction and video recording. We repeated this experiment three times with bees from colonies $\mathrm{H} 4, \mathrm{H} 5$, and $\mathrm{H} 7$, each trial in a different field season. In the experiment with colony H4, we performed two trials (approximately two weeks apart) that gave similar results and were eventually pooled in our analyses.

\subsection{Data analyses}

We attempted to analyze the video records in a blind procedure, such that the observer was not aware of the date and time of observation (in the first experiment with colony $\mathrm{H} 4$, the observer was aware of the time the film was video recorded, but we had no specific prediction as for when aggression is high). We recorded two clearly identified behaviors: biting and stinging attempts. "Biting" was defined as a sharp dart or forward movement toward the bumblebee, which then typically was followed by bumblebee withdrawal. The associated mandible movement was observed in many biting events and was useful for the initial characterization of this behavior, but was not a condition for recording an observed event as biting. A "stinging attempt" was defined as a honeybee grasping the bumblebee with its legs and mandibles while folding its abdomen in a typical stinging posture. In cases in which it was difficult to identify discrete stinging attempts, we counted every 2 seconds during which a bee showed this behavior as a single stinging attempt. In order to minimize the effect of diurnal/circadian variation in arousal state on our indices for aggressiveness, we divided the number of bites and stinging attempts by the time elapsed from the moment the honeybees identified the introduced bumblebee (which is influenced by their level of arousal - bees typically respond faster when awake). We also corrected our indices by the number of live honeybees in the cage. In the experiment with bees from colony $\mathrm{H} 5$, we further corrected our indices by the number of awake bees. A bee was defined as awake if it moved around, stood still but was moving its 
head or wings, or moved its antennae $>20$ time/min (Eban and Bloch, unpubl. data). We used two indices for latency: the time elapsed from bumblebee introduction until it was first attacked, and the time until the first stinging attempt. We tested the influence of time on the level of aggressiveness with the non-parametric Kruskal-Wallis test because sample size was small and data did not fit normal distribution.

\section{RESULTS}

As in other studies on group aggression, our results were very variable. Nevertheless, in all three trials there was a consistent trend of longer latency to first attack during the subjective night. The variation over time was significant in both LD and DD for the experiment with colony $\mathrm{H} 4(P<0.05$, Fig. 1 , upper panel). By contrast, a similar trend was not obtained in LD in the experiment with bees from colony H7. The results were similar for the latency before the first stinging attempt (data not shown). To further characterize the level of aggressiveness, we measured the number of stinging attempts and biting events per bee (corrected for the time elapsed since the honeybees identified the introduced bumblebee). In two of the three experiments (with bees from colonies $\mathrm{H} 4$ and $\mathrm{H} 7$ ), the number of stinging attempts varied over time in DD with higher levels during the subjective day $(P<0.05$; Fig. 2). A similar variation was not seen in these two experiments when bees were observed in LD, where the effect of time was not statistically significant. In the experiment with colony H5, the intensity of stinging attempts did not vary with time even when we corrected this index for the number of awake bees (Fig. 2, and data not shown). In the trial with bees from colony $\mathrm{H} 5$, in which we recorded the number of awake bees in each observation, more guard bees showed sleep-like behavior during the subjective night (Kruskal Wallis test, $P<0.05$; data not shown). The influence of time and illumination regime on biting intensity appears similar to the stinging attempts, but the time-related variation in constant darkness did not reach statistical significance (colony $\mathrm{H} 4, P=0.058$; colony $\mathrm{H} 7$, $P=0.077$; Fig. 3.).

\section{DISCUSSION}

Our observations suggest that both the latency before the first attack and the number of stinging attempts vary with time under constant conditions, at least for bees from some source colonies ("genotypes"). Variation over the day under constant conditions commonly implies that the endogenous circadian clock influences the tested phenotype. Thus, these observations are consistent with the hypothesis that the circadian clock influences guard aggressiveness. Nevertheless, caution is required. First, variation in arousal state may contribute to the increased latency before the first attack during the night. Honeybee foragers have a sleep-like state with reduced muscle tonus and an elevated response threshold (Kaiser and Steiner-Kaiser, 1983; Kaiser, 1988; Eban and Bloch, submitted). Our detailed observations in the experiment with colony $\mathrm{H} 5$ now extend these findings to guard bees in small groups in the laboratory; awake bees can detect an intruder and respond faster than sleepy bees. Second, in measuring biting and stinging behavior, we indeed reduced the influence of arousal state, but the observed variation in DD was not seen in LD. The apparent disparity between the observations in LD and DD may indicate that both light and the circadian clock influence the expression of overt aggression. However, it is also possible that this is a mere reflection of the high intrinsic variability in the measurements of aggressiveness in our bioassay. Thus, we feel that additional studies are necessary to differentiate between these two explanations.

Even with the caveats mentioned above, our results provide some of the best available support for the hypothesis that the circadian clock influences animal aggression. The scarcity in information on circadian influences on the level of aggressiveness is quite surprising given the considerable amount of research on the mechanisms and modulation of aggressive behaviors in general. This stems, at least in part, from the difficulty in developing reliable measurements for aggressiveness, a phenotype that is influenced by many internal and external factors, and is therefore very variable. There is evidence 

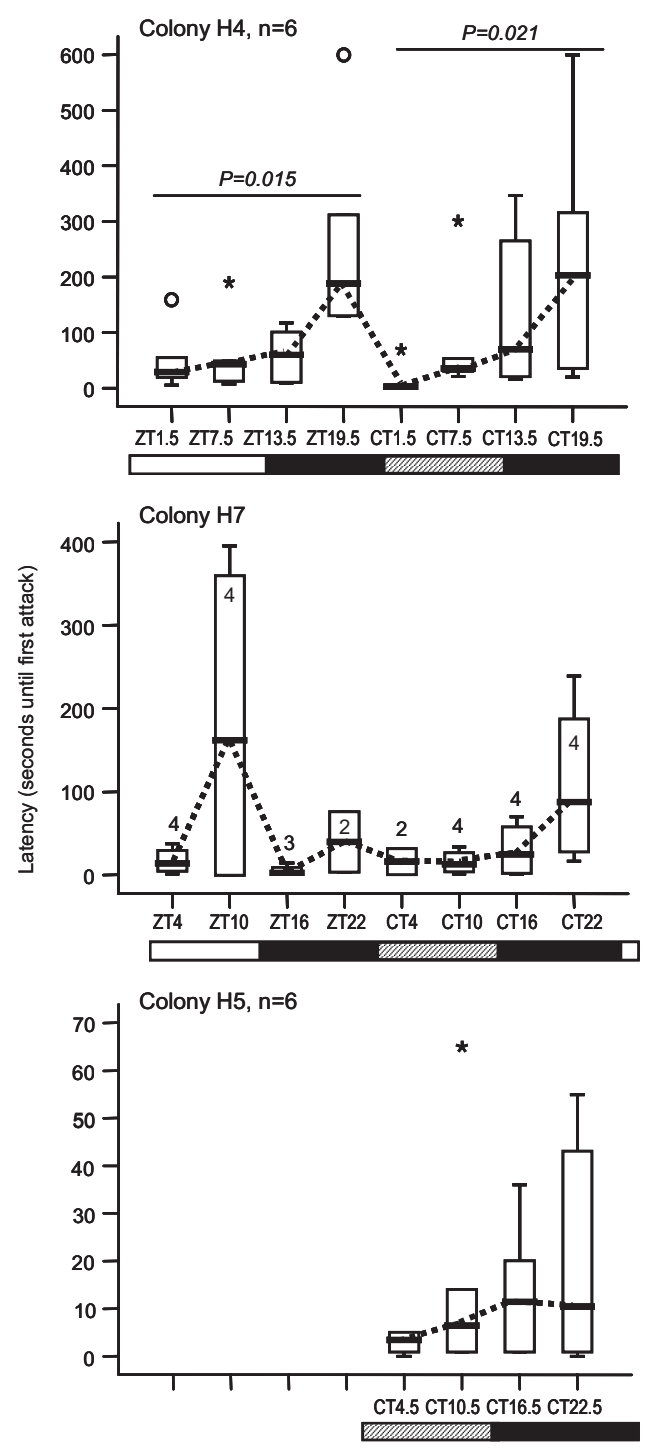

Figure 1. The influence of time and illumination regime on the latency before the first attack. The plots depict the time elapsed (s) from the introduction of a bumblebee until it was first attacked by a group of honeybee guards. Upper panel, experiment with bees from colony $\mathrm{H} 4$ ( $\mathrm{n}=6$ groups/time point); middle panel, experiment with bees from colony $\mathrm{H} 7$ (sample size within or above bars); lower panel, experiment with bees from colony H5 $(n=6)$. Details of the box plot presentation: the bar in the middle of the box represents the median, the upper part of the box is the 75th percentile, the lower part is the 25th percentile. The error bars extend to the highest and lowest values, excluding outliers. The circles depict outliers with values between 1.5-3 times the range of the box (25th-75th percentile); asterisks are extreme values which are $>3$ times this range. The thick dashed line connects the medians of successive time points. The rectangles at the bottom of the plots show the illumination regime: open rectangle $=$ day (light phase); filled rectangle $=$ night or subjective night; rectangle with diagonal lines $=$ subjective day. $\mathrm{ZT}=$ Zeitgebers time, ZT0-12 is the time of light on; CT = circadian time, time in constant darkness corresponding to ZT (CT0$12=$ subjective day). A horizontal line and a $P$-value above bars show statistically significant $(P<0.05)$ or almost significant $(0.05<P<0.1)$ variation in a Kruskal-Wallis non-parametric test. 

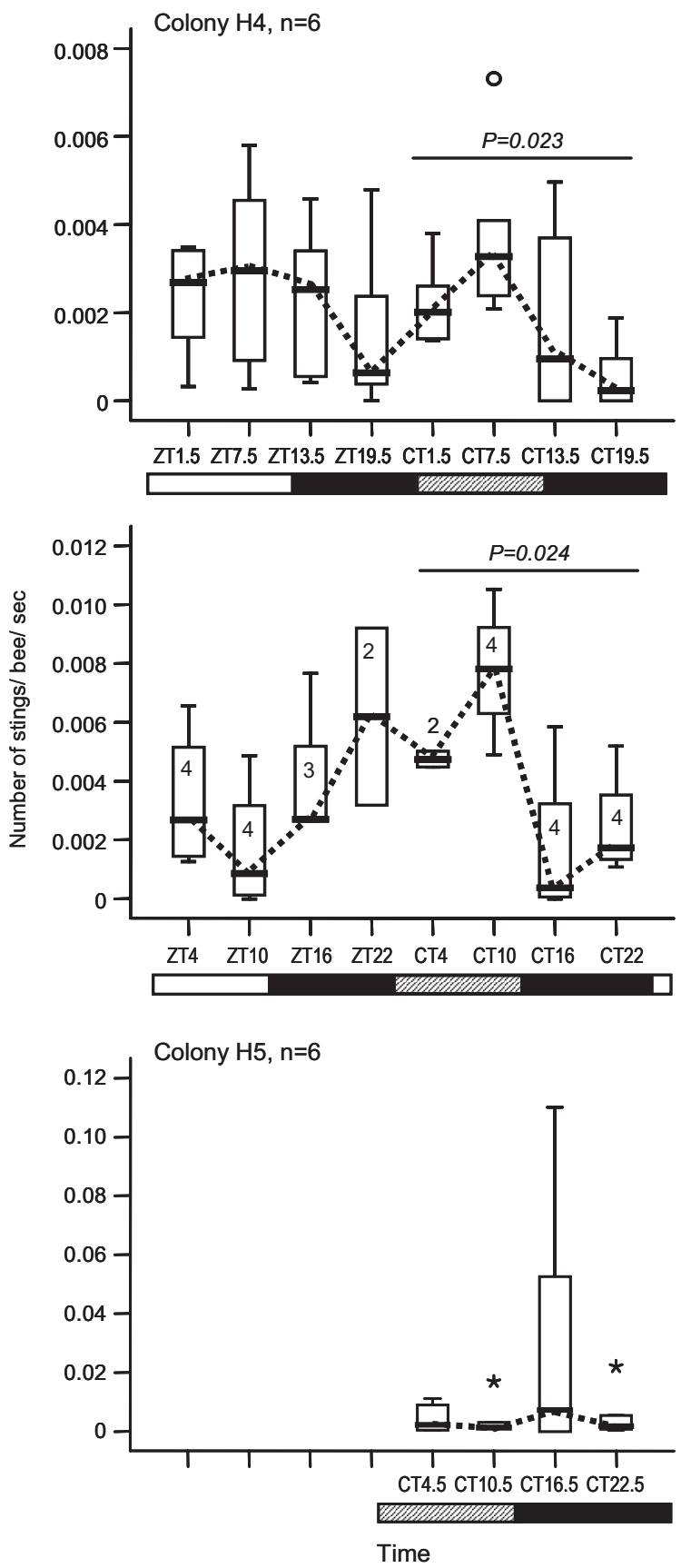

Figure 2. The influence of time of day and illumination regime on stinging behavior of guard honeybee workers. The plots depict the number of stinging attempts directed toward a bumblebee that was introduced into a cage with a group of honeybee guards. The number of stings per bee was divided by the time elapsed from the first attack. Details of plot as in Figure 1. 

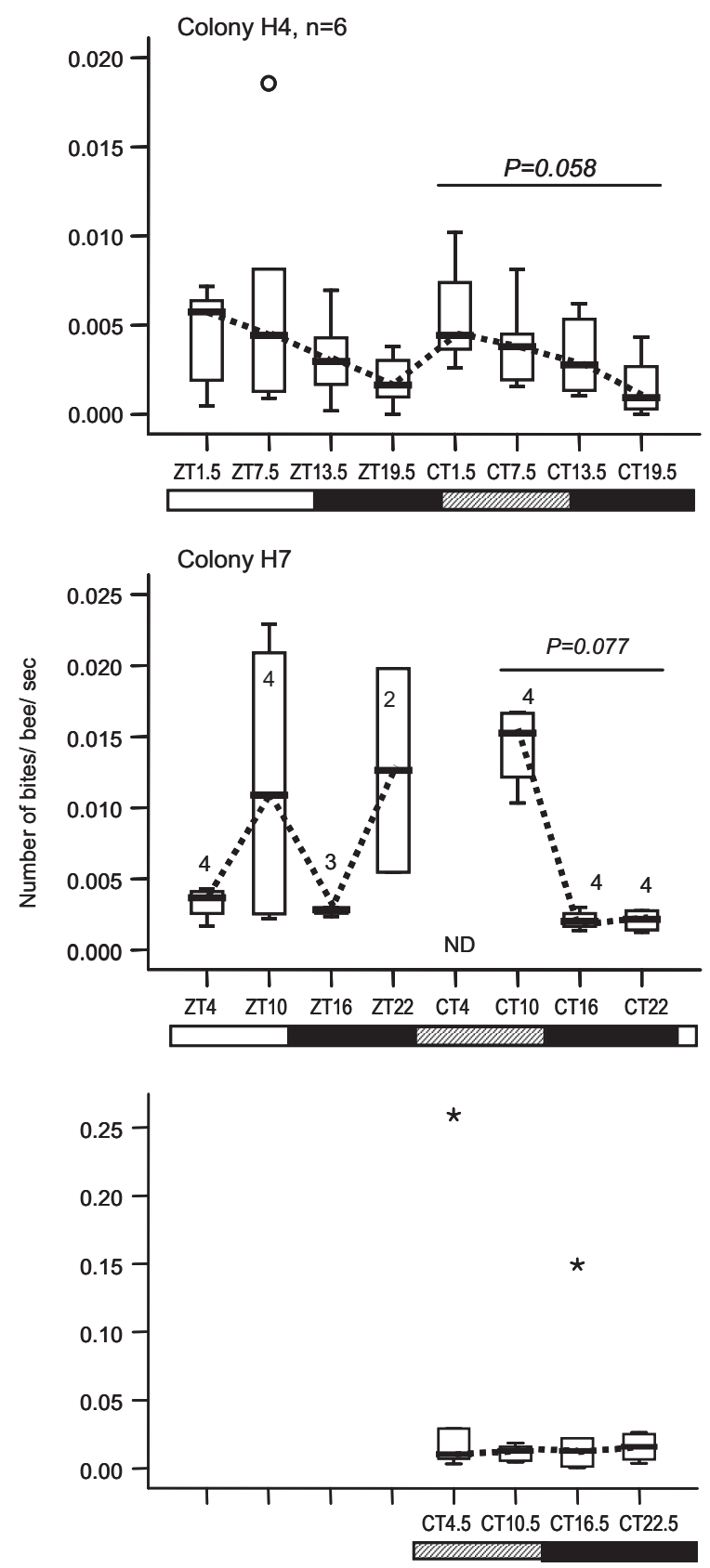

Time

Figure 3. The influence of time of day and illumination regime on biting behavior of guard honeybee workers. The number of bites per bee was divided by the time elapsed from the first attack. Details of plot as in Figures 1 and 2. 
that the level of aggressiveness varies with time of day in a range of species including mammals (e.g., pigtail monkeys, Martenson et al., 1977), birds (e.g., Black skimmers, Burger, 1981; Black-headed gull, Bukacinska and Bukacinski, 1994), fish (e.g., Japanese flounder, Sakakura and Tsukamoto, 2002), and spiders (orb-weaving spiders, Wells, 1944). However, since these studies were not carried out in a constant environment, it is virtually impossible to uncouple the influences of environmental and endogenous variables. Two studies with rodents are not consistent with circadian influences on aggression because day-night variation in aggressiveness was not significant in animals released to constant conditions (Sofia and Salama, 1970; Landau, 1975).

Colony defense is a social behavior, which might be influenced by non-linear interactions between individuals. For example, the release of alarm pheromones by a single individual increases the aggression of other bees and the probability that they will attack, sting, and release alarm pheromones themselves. This may generate a positive feedback loop with a nonlinear, rapid, and sharp elevation in the level of aggressiveness (Millor et al., 1999). Therefore, temporal variation in group aggression could result not only from changes in the aggressive behavior of each individual, but also from variation in the release or sensitivity to alarm pheromones, or other social signals.

An important challenge for future studies is finding whether similar variation over time occurs naturally in field colonies. For example, is guarding at the hive entrance less stringent at night? Another possibility is that circadian rhythmicity in guards is context-dependent and differs between the hive and the laboratory in which we performed our aggression assay. Such context dependence of circadian rhythmicity was recently discovered for nurse bees that care for the brood around-the-clock but show strong circadian rhythms in locomotor activity shortly after transfer from the hive to individual cages in a constant laboratory environment (Shemesh et al., 2007). An intriguing possibility is that worker aggression is influenced by the division of labor, with bees involved in colony defense, such as foragers, "soldiers" (Breed et al., 2004), and guards, having their peak aggressiveness at different times during the day.

\section{ACKNOWLEDGEMENTS}

We thank the Israel-US Binational Science Foundation (BSF) grant 2003-151 (to GB), the German Israeli Foundation (GIF) grant 1.822.73.1/2004 (to GB), and the Joseph H. and Belle R. Braun Senior Lectureship in Life Sciences (to GB) for financial support, Rafi Nir for expert beekeeping assistance.

Variation dans le temps du comportement de défense en groupe des abeilles (Apis mellifera) gardiennes.

Apis mellifera / agressivité / défense de la colonie / rythme circadien / division du travail

Zusammenfassung - Zeitliche Variation des Gruppenverteidigungsverhaltens von Wächterinnen der Honigbienen (Apis mellifera). Die Kolonieverteidigung ist eine der grundlegenden Aufgaben innerhalb von Insektensozietäten. Trotz der in letzter Zeit erreichten Fortschritte im Verständnis des Verteidigungsverhaltens ist nur wenig über dessen zeitliche Organisation bekannt. Bei Honigbienen sind die am besten organisierten Verteidiger die Wächterinnen. Dies sind Arbeiterinnen mittleren Alters, die typischerweise am Stockeingang patrouillieren, Ankömmlinge inspizieren und jeden mutmaßlichen Räuber oder Parasiten angreifen. Um zu bestimmen, ob ihre Aggressivität im Tagesverlauf variiert, synchronisierten wir kleine Gruppen von Wächterinnen im Labor unter einem hell-dunkel Tagesverlauf (LD) und nahmen ihre Aggression gegenüber eindringenden Hummeln sowohl unter Bedingungen von LD als auch von ständiger Dunkelheit (DD) in Videoaufnahmen auf. Wir wiederholten das Experiment dreimal mit Bienen aus jeweils verschiedenen Völkern. Wie in anderen Untersuchungen über Gruppenaggression variierten unsere Anzeiger der Aggressivität sehr stark. In einer der drei Untersuchungen war die Verzögerung vor dem ersten Angriff während der Nacht bei LD oder der subjektiven Nacht bei DD länger; in den zwei anderen Versuchen unter DD wurde ein ähnlicher Trend beobachtet (Abb. 1). In zwei der drei Tests war die Anzahl der Stechversuche während der subjektiven Nacht unter DD höher, bei LD war dies nicht der Fall (Abb. 2). Ein ähnlicher Trend wurde bei einem weiteren Anzeiger der Aggressivität, der Anzahl der Beißversuche, sichtbar (Abb. 3). Dies könnte darauf hinweisen, dass externe Faktoren, wie das Licht und die endogene Uhr, komplexe 
und zum Teil gegensätzliche Einflüsse auf die offene Aggression haben. Allerdings können wir nicht ausschließen, dass die Variation der Beobachtungswerte bei LD und DD sowie zwischen Versuchen mit Bienen aus unterschiedlichen Völkern aus der insgesamt hohen Variabilität der Aggressivität in unserem Testassay hervorgerufen wurde. Insgesamt unterstützen unsere Ergebnisse aber zumindest in Teilen die Hypothese, dass die zirkadiane Uhr die Aggressivität der Wächterinnen beeinflusst. Unsere Untersuchung zeigt die Berechtigung der Frage, ob die zirkadiane Uhr die Wächteraggressivität beeinflusst und die Möglichkeit, diese experimentell in weiteren Tests zu untersuchen.

\section{Honigbienen / Aggression / Kolonieverteidi- gung / zirkadianer Rhythmus / Arbeitsteilung}

\section{REFERENCES}

Bloch G. (2008) Plasticity in the circadian clock and social organization, in: Gadau J., Fewell J. (Eds.), Organization of Insect Societies - From genomes to socio-complexity, Harvard University Press (in press).

Bloch G., Robinson G.E. (2001) Reversal of honeybee behavioral rhythms, Nature 410, 1048.

Breed M.D. (1983) Nestmate recognition in honey bees, Anim. Behav. 31, 86-91.

Breed M.D., Smith T.A., Torres A. (1992) Role of guard honey bees (Hymenoptera: Apidae) in nestmate discrimination and replacement of removed guards, Ann. Entomol. Soc. Am. 85, 633-637.

Breed M.D., Guzman-Novoa E., Hunt G.J. (2004) Defensive behavior of honey bees: Organization, genetics, and comparisons with other bees, Annu. Rev. Entomol. 49, 271-298.

Bukacinska M., Bukacinski D. (1994) Seasonal and diurnal changes in aggression and territory size in the black-headed gull (Larus ridibundus L.) on islands in the middle reaches of the Vistula river, Ethology 97, 329-339.

Burger J. (1981) Aggressive behavior of Black Skimmers (Rynchops niger), Behavior 76, 20722.

Caron D.M. (2000) Moving bees, MAAREC Publication 5.3, University of Delaware.

Getz W.M., Smith K.B. (1983) Genetic kin recognition - honey bees discriminate between full and half sisters, Nature 302, 147-148.

Geva S., Hartfelder K., Bloch G. (2005) Reproductive division of labor, dominance, and ecdysteroid levels in hemolymph and ovary of the bumble bee Bombus terrestris, J. Insect Physiol. 51, 811-823.

Kaiser W. (1988) Busy bees need rest, too: Behavioral and electromyographical sleep signs in honeybees, J. Comp. Physiol. A 163, 565-584.
Kaiser W., Steiner-Kaiser J. (1983) Neuronal correlates of sleep, wakefulness and arousal in a diurnal insect, Nature 301, 707-709.

Kolmes S.A., Fergusson-Kolmes L.A. (1989) Measurements of stinging behavior in individual worker honeybees (Apis mellifera L.), J. Apic. Res. 28, 71-78.

Landau I.T. (1975) Light-dark rhythms in aggressive behavior of the male golden hamster, Physiol. Behav. 14, 767-774.

Martenson J.J., Oswald M., Sackett D., Erwin, J. (1977) Diurnal variation of common behaviors of pigtail monkeys (Macaca nemestrina), Primates $18,875-882$.

Meshi A., Bloch G. (2007) Monitoring circadian rhythms of individual honey bees in a social environment reveal social influences on postembryonic ontogeny of activity rhythms, J. Biol. Rhythms 22, 343-355.

Millor J., Pham-Delègue M., Deneubourg J.L., Camazine S. (1999) Self-organized defensive behavior in honeybees, Proc. Natl. Acad. Sci. (USA) 96, 12611-12615.

Moore A.J., Breed M.D., Moor M.J. (1987) The guard honey bee: ontogeny and behavioral variability of workers performing a specialized task, Anim. Behav. 35, 1159-1167.

Moore D. (2001) Honey bee circadian clocks: Behavioral control from individual workers to whole-colony rhythms, J. Insect Physiol. 47, 843857.

Moore D., Angel J.E., Cheeseman I.M., Fahrbach S.E., Robinson G.E. (1998) Timekeeping in the honey bee colony: integration of circadian rhythms and division of labor, Behav. Ecol. Sociobiol. 43, 147160.

Moritz R.F.A., Southwick E.E., Breh M. (1985) A metabolic test for the quantitative analysis of alarm behavior of honeybees (Apis mellifera L.), J. Exp. Zool. 235, 1-5.

Pearce A.N., Huang Z.Y., Breed M.D. (2001) Juvenile hormone and aggression in honey bees, J. Insect Physiol. 47, 1243-1247.

Sakakura Y., Tsukamoto K. (2002) Onset and development of aggressive behavior in the early life stage of Japanese flounder, Fish. Sci. 68, 854-861.

Shemesh Y., Cohen M., Bloch G. (2007) Natural plasticity in circadian rhythms is mediated by reorganization in the molecular clockwork in honeybees, FASEB J. 21, 2304-2311.

Sofia R.D., Salama A.I. (1970) Circadian rhythm for experimentally-induced aggressive behavior in mice, Life Sci. 9, 331-338.

Wells F.L. (1944) Diurnal behavioral cycle in spiders, Science 99, 513.

Winston M.L. (1987) The biology of the honey bee, Harvard University Press, Cambridge, Massachusetts. 